\title{
Paulo Freire e a educação popular na história do Serviço Social brasileiro (1980-2010)
}

\author{
Paulo Freire and popular education in the \\ history of brazilian social work (1980-2010)
}

\author{
Aline Maria Batista Machado ${ }^{a}$ \\ (1) https://orcid.org/0000-0002-1144-6011 \\ Andrêsa Melo da Silva ${ }^{b}$ \\ (D) https://orcid.org/0000-0001-7527-1460 \\ Graziela Mônica Pereira Tolentinob \\ (D) https://orcid.org/0000-0002-9123-6320
}

Resumo: $O$ presente artigo resgata a contribuição de Paulo Freire na história do Serviço Social brasileiro e destaca a educação popular como instrumento importante no trabalho e formação profissional do assistente social. Além disso, apresenta um levantamento das produções teóricas brasileiras que articulam as temáticas educação popular e Serviço Social no recorte temporal de 1980-2010, assinalando a área mais produtiva; perfil dos autores; ano, tipo, região, temática e abordagem das produções.

Palavras-chave: Paulo Freire. Serviço Social. Educação popular.

\begin{abstract}
This article recounts the contribution of Paulo Freire in the history of Brazilian Social Service and highlights popular education as an important tool in the work and professional training of the social worker. In addition, it presents a survey of the Brazilian theoretical productions that articulate the themes of popular education and social service in the temporal cut of 1980-2010, highlighting the most productive area; profile of authors; year, type, region, thematic and approach to productions.
\end{abstract}

Keywords: Paulo Freire. Social Worker. Popular education. 


\section{Introdução}

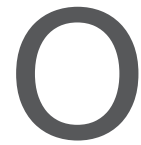

Brasil e o mundo conhecem o legado de Paulo Freire no campo da educação. Tanto é que desde 2012 esse grande intelectual segue patrono da educação brasileira, mesmo a contragosto de muitos conservadores que tentaram derrubar tal título em 2017, apoiados pela perspectiva do movimento Escola sem Partido, sob o argumento de que ele era um intelectual de esquerda e por isso não merecia a titulação. Fato que reflete bastante na conjuntura atual desde o golpe de Estado que derrubou a presidente Dilma Roussef em 2016.

Embora muitos assistentes sociais compreendam o valor das ideias de Paulo Freire acerca da educação popular, nem todos conhecem o grau de contribuição dessa educação no histórico processo de rompimento da profissão com o conservadorismo. Com o objetivo de fazer um balanço das produções teóricas que articulam Serviço Social e educação popular, nosso grupo de estudos e pesquisas realizou um levantamento bibliográfico acerca das produções brasileiras que articulam as duas temáticas, considerando o recorte temporal de 1980-2010. Das 101 instituições de nível superior investigadas, além das várias livrarias, sites e bibliotecas, só encontramos sessenta produções. Ou seja, para sete anos de investigação e um recorte temporal de três décadas, consideramos um resultado incipiente.

Praticamente depois que a profissão se aproximou das ideias de Karl Marx (1818-83), foram abandonados os debates teórico-críticos que envolvem a educação popular. É como se o legado de Freire tivesse sido esquecido ou fosse obsoleto. Daí muitos alunos dos cursos de Serviço Social o desconhecerem, bem como sua contribuição à profissão. Diante disso, antes de abordarmos a importância desse autor e da educação popular na história do Serviço Social, dois pontos devem ser considerados: que o ecletismo teórico dos intelectuais nos anos de 1970 afastou nossa profissão das ideias de Freire e que o pensamento desse intelectual avançou ao longo dos anos.

Com relação ao ecletismo teórico, Netto (1991) já destacou que nesse processo a profissão alcançou uma "intenção de ruptura" com o conservadorismo, mas não uma ruptura de fato, visto que essa só ocorreria mais tarde, com a aproximação das leituras das fontes originais de Karl Marx. 
Contudo, podemos dizer que o foco em Marx ofuscou o diálogo com Freire, mas "re-pensar o trabalho de mobilização e educação popular [...] não se confunde com uma inócua ressurreição de um passado perdido. Exige uma releitura crítica da tradição profissional” (Iamamoto, 2002, p. 33).

Segundo Scheffer (2013, p. 299), "o pensamento freiriano e sua relação com o marxismo é cercado de polêmicas, pois muitos apontam que sua elaboração não tem relação com a vertente marxista; contudo" continua a autora, "para outros se percebe claramente esta interlocução, principalmente no livro Pedagogia do oprimido" (Ibidem). A despeito dessa divergência, cabe destacar que Freire adota a categoria práxis como uma das categorias fundamentais da educação popular. Ao destacar essa categoria filosófica central do marxismo, o autor demonstra uma visão crítica oposta ao idealismo. Daí concordarmos com Scheffer (2013, p. 299) quando afirma que "as análises freirianas têm uma construção plural que a tornou original no pensamento social da América Latina". Nesse sentido, partimos do pressuposto de que o ecletismo não estava em Freire, e sim nos autores do Serviço Social que outrora interpretaram equivocadamente suas ideias.

Quanto ao avanço das ideias de Freire ao longo de sua trajetória intelectual, Scheffer (2013) destaca que a partir de 1968, com a obra Pedagogia do oprimido, "podemos identificar um novo ângulo de análise representado na ruptura com a lógica de conciliação de classes, ou seja, assumiu a radicalidade voltada ao fortalecimento da classe trabalhadora” (Scheffer, 2013, p. 299).

Em 2017 fez vinte anos da morte de Freire, mas seu legado na área da educação tornou-se imortal, não só pelo seu método de alfabetização, "método Paulo Freire", que estimulava a politização dos educandos, negando "a mera repetição alienada e alienante de frases, palavras e sílabas, ao propor ao alfabetizante 'ler o mundo' e 'ler a palavra', leituras [...] indissociáveis" (Freire, 1996, p. 40), mas, sobretudo, por sua contribuição acerca da educação popular.

Educação popular é a que, substantivamente democrática, jamais separa do ensino dos conteúdos o desvelamento da realidade. É a que estimula a presença organizada das classes sociais populares na luta em favor da transformação democrática da sociedade, no sentido da superação das injustiças sociais [...] 
critica também a natureza autoritária e exploradora do capitalismo. (Freire, 2007, p. 103-105)

O debate ou as práticas de educação popular geralmente se apresentam no campo de atuação dos assistentes sociais que trabalham com comunidades, organização e mobilização popular, sobretudo em ONGs articuladas aos movimentos sociais, onde esse tipo de educação se refugiou desde o período da ditadura militar, visto que naquele contexto histórico passou a ser considerada subversiva, uma vez que criticava o sistema capitalista e o golpe militar de 1964. É nessa conjuntura que o pensamento de Paulo Freire ganha força junto ao Serviço Social brasileiro.

\section{A relação do Serviço Social com Paulo Freire e a educação popular}

A relação da profissão de Serviço Social com Paulo Freire começa quando ele recebe o convite para atuar no recém-criado Serviço Social da Indústria - Sesi na cidade do Recife-PE, no ano de 1947. Para o autor, foi "o tempo do Sesi, indiscutivelmente um tempo fundante" (Freire, 2011, p. 26), o que é reforçado quando fala de sua principal obra nos seguintes termos: "A Pedagogia do oprimido não poderia ter sido gestada em mim só por causa da minha passagem pelo Sesi, mas a minha passagem pelo Sesi foi fundamental. Diria até que indispensável a sua elaboração" (Ibidem). Embora essa relação tenha início na década de 1940, a influência de seu pensamento na história do Serviço Social brasileiro só se dará por volta das décadas de 1960 e 1970.

“Segundo Netto (2002), Abreu (2002) e Faleiros (2005), a aproximação do Serviço Social com as ideias de Paulo Freire na América Latina se dá no decorrer do Movimento de Reconceituação da profissão (entre as décadas de 1960 e 1980)". (Machado, p. 2013, p. 124). Em 1964 Freire participou como convidado principal na mesa de abertura do II Encontro das Escolas de Serviço Social do Nordeste, "o que significou uma 'aliança simbólica' da categoria profissional com o pensamento freiriano" (Scheffer, 2013, p. 297). Para a autora, 
as primeiras aproximações do Serviço Social com as ideias do educador se deram em dois aspectos: primeiro, pela vinculação de Freire ao movimento católico (de viés progressista), e, segundo, por meio das propostas e ações de desenvolvimento de comunidades ligadas à educação de base de adultos.

Aguiar (1995, p. 105) afirma que "a partir da década de 60 temos assistentes sociais cristãos que continuam assumindo a visão tradicional da Igreja e os que assumem uma posição mais progressista". Por isso é relevante destacarmos que o supracitado Encontro já sofria influência dos assistentes sociais mais engajados nas lutas populares, o que explica Freire na mesa de abertura. "Em 1963 e 1964, realizaram-se encontros das escolas de Serviço Social do Nordeste. E as colocações e posições foram no sentido de maior comprometimento com as lutas do povo e reformulação do Serviço Social" (Aguiar, 1995, p. 103).

De acordo com Goulart (1997) e Oliveira (2016), o encontro de 1963 ocorreu na cidade de Aracajú (SE) e o de 1964 em Campina Grande (PB). "Foi quando se questionou o funcionalismo e se iniciou forte debate sobre a reconceituação" (Goulart, 1997, p. 196). E no seio desse debate:

A concepção freiriana sobre conscientização, ao valorizar o saber popular, diferia da concepção dominante, visto que negava a função de intelectual como portador e produtor de consciência [...]. Essa concepção se consolida durante os trabalhos do autor, após o exílio, com obras que traduzem uma maior aproximação ao catolicismo radical e a influxos marxistas. É justamente nesse período que a influência de Freire se refrata no Serviço Social por meio do método BH. (Gomes, 2011, p. 56)

O “método BH" surge em Belo Horizonte (MG) entre 1972 e 1975, como alternativa ao tradicionalismo profissional no processo de "intenção de ruptura". Seus formuladores consideravam que o objeto de sua atuação era "a ação social da classe oprimida", seus objetivos meios era "a conscientização, a capacitação e a organização" e seus objetivos fins era a "transformação da sociedade e do homem". Cabe dizer que se o objeto de atuação da profissão fosse mesmo a "ação social da classe oprimida", como pensavam os formuladores do "método BH", os resultados da intervenção dos assistentes sociais ficariam 
totalmente submetidos à ação social dessa classe. Com isso, entendia-se que se tal classe não agisse, a profissão de Serviço Social era a responsável por tal imobilismo. O que significa que naquela época a profissão abarcava uma responsabilidade enorme pela transformação social, quando, na verdade, profissão nenhuma pode assumir tamanha tarefa, pois a transformação da sociedade advém da luta de classes, e não da luta de uma profissão. Ademais, ainda que a educação popular contribua com o processo de conscientização dos sujeitos sociais, se esses sujeitos, por meio da práxis em processos mais amplos e complexos, não se dispuserem a transformar o mundo, isto é, a participarem da luta de classes, nada muda. Daí o Serviço Social não poder tomar a "ação social da classe oprimida" como objeto de atuação.

Acontece que desde aquela época a perspectiva freireana já afirmava que na qualidade de educador popular, o profissional pode estimular a conciência crítica e o desvelamento da realidade, mas não se responsabilizar pela ação do educando, pois tal ação já não cabe ao profissional, mas os assistentes sociais envolvidos nesse processo de luta contra uma conjuntura de repressão política e militar não captaram esse entendimento. Ao buscar analisar os pressupostos do método, Batistoni (2017, p. 138 e 142) afirma:

A experiência da Escola mineira emergiu na primeira metade dos anos de 1970, no imediato após o AI-5, contexto em que a repressão e violência policial militar institucionalizaram-se [...]. Livre de contestação, a ditadura militar garantira as condições sob as quais o grande capital monopolista, nacional e estrangeiro alcançaria as mais altas taxas de lucros [...]. Na equipe de docentes assistentes sociais destaca-se a presença de alguma experiência e contato com práticas do Serviço Social rural, de educação popular, vinculadas ao Movimento de Educação de Base, orientada pela pedagogia de Paulo Freire, e de práticas institucionais de desenvolvimento de comunidade.

Conforme Gomes (2011, p. 67), "embora Freire não seja sequer citado no texto de $\mathrm{BH}$, conseguimos identificar inúmeros pontos de contato”. $\mathrm{E}$ complementa: "BH utiliza formas de organização (discussão de grupos, círculos de cultura) desenvolvidos por Paulo Freire e outros instrumentos de investigação criados pela população" (Ibidem). De fato, os textos que 
compreendem o método BH davam indícios da influênia de Freire, especialmente os registrados na obra Textos de Serviço Social, de Leila Lima Santos, publicada pela Cortez em 1982. Netto (1991, p. 149) anunciou a possibilidade da influência freireana no Serviço Social ao dizer: "Cabe observar a abrangente e profunda influência do pensamento do pedagogo brasileiro sobre as vanguardas [...], salvo erro nosso, boa parcela da produção [...] depende inteiramente das formulações de Freire". Somente em 2007 essa suposição será confirmada pela própria Leila Santos em entrevista à revista Em Pauta:

A Escola de Serviço Social de Belo Horizonte (PUC/MG) viveu um processo muito interessante nos anos 70 e contou com um grupo de qualificados e comprometidos professores tanto na área de Serviço Social como das Ciências Sociais, todos eles adeptos dos ventos "cambiantes" da reconceituação latino-americana. Muitos de nós, diretores e vários professores, estávamos inspirados nos postulados religiosos do Concílio Vaticano II, na Teologia da Libertação, nos princípios filosóficos da educação popular de Paulo Freire... (Santos, 2007, p. 166)

Esse depoimento revela o ecletismo nos pressupostos do método $\mathrm{BH}$, o qual foi destacado por Netto (1991), mas também revela a contribuição de Freire na história da construção da ruptura do Serviço Social brasileiro. Ao contextualizar o esforço de ruptura do Serviço Social com o conservadorismo naquela época, Silva (2009) destaca a educação popular como um dos eixos articuladores da proposta metodológica de ruptura. "Nessa direção, o assistente social se propõe a trabalhar com as classes populares, viabilizando reflexões acerca do seu dia a dia, contribuindo para sistematização do saber popular como forma de resistência" (Silva, 2009, p. 178). É nesse período de reconceituação que houve os equívocos teóricos. Entretanto, só "a partir de então criaram-se as bases, antes inexistentes, para pensar-se a profissão sob a lente de correntes marxistas” (Netto, 1991, p. 149).

Na década de 1980 a relação do Serviço Social latino-americano com a educação popular continua, porém com o diferencial de que não se vivia mais a repressão do regime militar. Em 1986 a Associação Brasileira de Ensino de Serviço Social - Abess (hoje Abepss) promoveu o Seminário Nacional sobre Movimentos Sociais, Educação Popular e Serviço Social, o 
qual ocorreu na cidade de Salvador (BA). Segundo a Abess (1988), nesse seminário um dos eixos de interesses foi "movimentos sociais e a educação popular", visto como tema desafiador daquela conjuntura e por isso tido como fundamental "à prática contraditória dos profissionais de Serviço Social na América Latina, no esforço por uma articulação orgânica ao projeto popular alternativo" (Abess, 1988, p. 4).

Na década de 1990 a educação popular não esteve muito em pauta nos debates acadêmicos da área de Serviço Social; entretanto, na década atual, esse debate vem sendo retomado. Em 2009 o CFESS organizou na Universidade Estadual do Rio de Janeiro o seminário O Trabalho do(a) Assistente Social no Suas, e uma das mesas de debate abordou o tema "Assistência social, mobilização e educação popular”. E em 2013 lançou o texto "Subsídios para a atuação na política de educação", destacando a necessidade de problematizar as particularidades da educação popular junto aos(às) assistentes sociais que atuam na área da educação.

Apesar de a produção sobre esse tipo de educação ser incipiente na formação profissional do assistente social, a educação popular continua presente em seu campo de atuação. Nesse sentido, a provocação de Iamamoto (2002) que trouxemos no início deste texto, de que é preciso repensar o trabalho de mobilização e educação popular no nível da formação profissional, é extremamente oportuna, especialmente quando explica que isso deve ocorrer reapropriando-se das conquistas e habilitações perdidas no tempo e, ao mesmo tempo, superando-as. Assim sendo, ampliar o debate acerca da importância da educação popular para o Serviço Social e realizar pesquisas no âmbito das ONGs e demais instituições que atuam com esse tipo de educação é fundamental para a formação e a prática dos estudantes e profissionais da área. Até porque, conforme Freire (2007, p. 103-105), "a educação popular posta em prática em termos amplos, profundos e radicais, numa sociedade de classes, se constitui como um nadar contra a correnteza". O que converge com os princípios do Projeto Ético-Político do assistente social.

Ao abordarem a convergência entre Serviço Social e educação popular, tanto Machado (2012), quanto Oliveira et al. (2013) apontam a relevância dessa relação no fortalecimento das dimensões teórico-metodológica, ético-política e técnico-operativa do exercício profissional do Serviço Social, 
com vistas a reafirmar o saber popular, respeitar a autonomia dos sujeitos e construir com eles alternativas críticas de intervenção e mobilização social. Enquanto a primeira autora ensaia um debate a partir de reflexões teórico-críticas, trazendo elementos históricos e conceituais acerca do tema, as outras autoras não só acompanham a linha de pensamento de Machado (2012), como a complementa a partir de uma experiência empírica no campo da extensão universitária, qual seja: o Projeto de Extensão Liga de Saúde da Família, que, conforme afirmam, teve como parceria a Secretaria Municipal de Saúde de Fortaleza, a Universidade Federal do Ceará e a Universidade Estadual do Ceará, cujo objetivo geral foi possibilitar um processo de ensino-aprendizagem aos estudantes e docentes dos cursos de graduação da área da saúde, mediado pela realidade social vivenciada pela população e pelo contexto das unidades básicas de saúde da família. Com a "metodologia da educação popular, os profissionais de Saúde [...] passavam a construir uma relação diferente com as classes populares [...] contribuir para problematizar os diferentes saberes, científico e popular" (Oliveira et al., 2013, p. 391-392).

Se no exercício profissional o(a) assistente social se defronta com possibilidades de atuar com a educação popular, o ideal é que ele(a) saiba o que ela significa desde a sua formação acadêmica. Além disso, a educação popular nos possibilita práticas mais críticas e democráticas, opostas a ações verticalizadas, em que só se considera o saber do profissional, restando ao seu público-alvo o mero papel de espectador, e não de sujeito social.

Portanto, na história do Serviço Social cabe resgatarmos dois aspectos importantes, a fim de seguirmos avançando no tempo presente: primeiro, diferentemente do contexto do desenvolvimento do método de $\mathrm{BH}$, que entendia que o objeto de atuação da profissão era a "ação social da classe oprimida", hoje as diretrizes curriculares da formação profissional já nos norteiam que o objeto da profissão é a questão social em suas mais variadas expressões; portanto, nesse equívoco não podemos mais cair. Segundo, também não devemos cair num outro equívoco da profissão dos anos 1970, apontado por Netto (1991, p. 285) como "equívoco demagógico de supor que a verdade residia no saber da população". O autor avalia que tal equívoco foi generalizado na profissão, mas não pelos formuladores do método $\mathrm{BH}$, que já criticavam esse desacerto. 
Quando Paulo Freire toma o saber popular como uma das categorias constituintes da educação popular, segue no pensamento de que o(a) educador(a) "progressista, ainda quando, às vezes, tenha de falar ao povo, deve ir transformando o ao em com o povo. E isso implica respeito ao 'saber de experiência feito' de que sempre falo, somente a partir do qual é possível superá-lo" (Freire, 2011, p. 38-39). E para que tal superação não fique apenas no idealismo, visto que compreende que o processo de conscientização só se concretiza na práxis, afirma: "A mudança da compreensão, de importância fundamental, não significa, porém, ainda, a mudança do concreto” (Freire, 2011, p. 38). Por ter sido criticado como idealista, Freire faz uma autocrítica no ano de 1992 em uma passagem do livro Pedagogia da esperança, assumindo que na obra Em educação como prática da liberdade, de 1967, escrita antes de Pedagogia do oprimido, se equivocou por ter dado a entender que desvelar a realidade já significava a sua transformação.

Portanto, o autor amadureceu em sua perspectiva teórico-crítica, trazendo novas contribuições no campo da educação popular. Desse modo, tal qual a profissão do Serviço Social, a educação popular teve seus percalços. Daí, portanto, os descompassos na relação entre Freire e o Serviço Social. Porém atualmente essa relação pode e deve ser repensada, como nos indica os autores aqui abordados.

\section{A produção teórica que articula as temáticas Serviço Social e educação popular no Brasil (1980-2010)}

Embora a educação popular não seja uma temática nova na área de Serviço Social, percebemos que ela tem sido inexpressiva nas produções teóricas da área, mas, concomitantemente, é uma "demanda em potencial". Nessa perspectiva, realizamos um levantamento das produções teóricas brasileiras que articulam as temáticas educação popular e Serviço Social no recorte temporal de 1980 a 2010, a fim de identificarmos: a área que mais vem produzindo essa articulação temática (Serviço Social ou educação); o perfil dos autores; o ano da produção; o tipo (livro, capítulo de livro, revista científica, anais de evento, tese, dissertação de mestrado ou trabalho de 
conclusão de curso); e, por fim, os locais onde tais produções foram publicadas (cidade e região brasileira).

[...] a produção do conhecimento, qualquer que seja o campo do saber, não pode prescindir do esforço sistemático de inventariar e fazer balanço sobre aquilo que foi produzido em determinado período de tempo e área de abrangência. Isso é o que se convencionou chamar de "estado de conhecimento" ou "estado da arte". (Sposito, 2009, p. 7)

A nossa investigação teve início em 2011, e cada integrante do grupo de pesquisa se responsabilizou por examinar um ou dois estados brasileiros porém, iniciamos com as universidades públicas e as confessionais, como as PUCs (Pontifícias Universidades Católicas) e depois seguimos para as faculdades particulares. Fizemos o levantamento das produções acadêmicas (monografias, dissertações e teses) de 73 universidades (públicas e privadas), dez faculdades, quatro PUCs, quatro centros universitários, oito institutos federais, uma escola superior e uma fundação, perfazendo um total de 101 instituições situadas em todo o Brasil. Também houve pesquisas em bibliotecas, livrarias, anais de congressos e internet, sobretudo no banco de teses do site da Capes (Coordenação de Aperfeiçoamento Pessoal de Nível Superior). Além disso, contamos com duas fontes de pesquisa preciosas: a monografia de graduação de Almeida Filho (2012) e a tese de doutorado de Vargas (2014), visto que ao também fazerem análises das produções que articulam educação popular e Serviço Social, a primeira revelou doze monografias publicadas na década de 1980 e a segunda revelou sete produções na década de 2000, todas inseridas em nosso banco de dados.

Por abranger todo o território brasileiro, nossa pesquisa exigiu sete anos de investigação. Entretanto, não obstante as instituições e demais fontes supracitadas, só encontramos sessenta produções publicadas entre os anos 1980 e 2010 que sinalizam ou aprofundam o tema educação popular e Serviço Social.

Os resultados da investigação revelaram que 95\% das produções são da área de Serviço Social e apenas 5\% da área de educação. Quanto ao período das publicações, nos surpreendemos, pois como o Serviço Social se aproximou 
da área da educação popular, sobretudo na década de 1970, nossa hipótese era de que a década seguinte, 1980, seria a de maior produção sobre essa temática, porém os dados demonstraram que a maior parte da produção, $48 \%$, tem sido na década atual, enquanto 42\% ocorreram na década de 1980 e apenas 10\% na década de 1990. Cabe ressaltar que até o ano de 1985 o país vivia uma conjuntura de ditadura militar (1964-85), período em que leituras atreladas a Paulo Freire e qualquer crítica ao sistema eram tidas como subversivas e, por isso, severamente punidas, o que certamente pode justificar a produção na década de 1980 não ser maioria.

No que se refere à baixa produção da década de 1990, entendemos que dois fatores podem ter contribuído. Primeiro, um de ordem interna, a já abordada crítica de Netto (1991) ao ecletismo teórico da área. Segundo, um fator de ordem externa, a queda do Muro de Berlim em 1989, visto que a partir disso muitos abandonaram a educação popular, pois como ela estimulava as mobilizações e lutas sociais para um novo modelo de sociedade, com a derrocada do Muro passaram a considerar o fim do "socialismo real" e, consequentemente, a impossibilidade de outro modelo de sociedade e, com isso, a crise da própria educação popular, que atualmente vem sendo ressignificada por determinados autores, os quais se afastam cada vez mais da questão de classe ou lutas de classes.

Sobre o tipo de produção, a maioria, 27\%, é de monografias de conclusão de graduação, seguidas de $18 \%$ de artigos completos publicados em anais de eventos científicos, 15\% de livros, 15\% de artigos publicados em revistas científicas da área do Serviço Social (Serviço Social \& Sociedade, Temporalis, Praia Vermelha e Cadernos Abess) ou site científico, 15\% configuram-se em dissertações de mestrado, 3\%, teses de doutorado, 3\%, entrevistas publicadas em revistas científicas da área do Serviço Social (Em Pauta e Serviço Social \& Sociedade), $2 \%$, capítulo de livro, e $2 \%$, livreto informativo.

No que diz respeito aos nove livros encontrados, a maioria foi publicada pela Cortez Editora. Consequentemente, o estado de São Paulo prevalece como lócus central dessa produção, porém, ainda que articulem as duas temáticas, a educação popular aparece de forma transversal, e não como tema principal, visto que geralmente é citada no contexto histórico da profissão ao abordarem o Movimento de Reconceituação do Serviço Social. Apenas 
o livro de autoria de José Paulo Netto critica a educação popular (devido ao ecletismo teórico da profissão na época do movimento de renovação da profissão). Os demais, que também apontam uma perspectiva crítica, consideram a importância da educação popular para os profissionais de Serviço Social, sobretudo quando estes atuam com a organização política da classe trabalhadora. $O$ único capítulo de livro, por sua vez, foi organizado e editado em 2009 na cidade de Brasília (DF) pelo CFESS em parceria com a Abepss. E com o apoio do Centro de Educação a Distância/Cead da Universidade de Brasília - UnB. Nele o tema da educação popular também aparece de forma transversal.

As duas teses de doutorado foram publicadas no estado de São Paulo (Unesp e PUC-SP), portanto, região Sudeste. Ambas são da área de Serviço Social que tomam a educação popular como tema transversal, e não central. Ainda não encontramos teses em outra década, apenas na atual, certamente pelo fato de as pós-graduações, em nível doutoral, serem mais recentes que os mestrados no nosso país. Nas nove dissertações de mestrado é possível perceber que o Sul se destaca, pois cinco são dessa região (três da PUC-RS, uma da UFSC, uma da Unisinos). Apenas duas são da região Norte (ambas da UFPA), e duas são de outras regiões (Centro-Oeste/UFG e Nordeste/UFPB). Ademais, seis são da área de Serviço Social e três da área de Educação. Nessas produções já é possível perceber que a maioria traz a educação popular como tema central desde o título, sendo notória a presença de categorias importantes da educação popular, como: diálogo, emancipação, formação, organização e resistência.

As monografias de conclusão de curso representam a maioria das produções, dezesseis no total, e todas da área de Serviço Social, sendo doze da região Nordeste (UEPB), duas do Sul (UFSC), uma do Centro-Oeste (UNB) e uma do Sudeste (UFJF). O que nos chama a atenção é que a Universidade de Estadual da Paraíba — UEPB, em Campina Grande (PB), se destaca com o maior número de produções da década de 1980. Como vimos no tópico anterior, foi em Campina que ocorreu em 1964 o II Encontro das Escolas de Serviço Social do Nordeste, onde se consolidou a aproximação com as ideias de Freire, que naquele momento ocupou a mesa principal do evento. Outro aspecto importante a ser destacado é que, ao contrário das produções em 
livros e capítulos, as monografias de graduação, assim como as dissertações de mestrado, tomam a temática da educação popular como foco central, e não transversal.

Os onze artigos publicados em anais foram divulgados em seis eventos científicos, dos quais um é da década de 1980 e dez da década de 2000, sendo que um foi publicado nos anais do V Congresso Brasileiro de Assistentes Sociais (1985), em São Paulo, três foram publicados nos anais do Seminário de Educação Popular, promovido pela Universidade Federal do Rio de Janeiro — UFRJ (2005), um publicado nos anais do XI Encontro Nacional de Pesquisadores em Serviço Social - Enpess, promovido pela Universidade Federal do Maranhão - UFMA (2008), um nos anais do IX CCHLA Conhecimento em Debate, promovido pela Universidade Federal da Paraíba — UFPB (2010), quatro publicados nos anais do XII Encontro Nacional de Pesquisadores em Serviço Social - Enpess, promovido pela Universidade Estadual do Rio de Janeiro - UERJ (2010), um outro no seminário nacional "O Trabalho do(a) Assistente Social no Suas”, também promovido pela UERJ, no ano de 2009 (embora só em 2011 tenha saído a publicação on-line pelo CFESS).

Com relação ao gênero dos autores das sessenta produções investigadas, $78 \%$ delas são de mulheres, apenas $18 \%$ são de homens, $2 \%$ foram escritas coletivamente por autores de ambos os gêneros, e 2\% não foi possível identificar por serem de autoria da antiga Abess. O fato de a maioria dos autores ser do sexo feminino certamente se justifica devido os cursos de Serviço Social e Pedagogia serem historicamente compostos em sua maior parte por mulheres, ainda que saibamos que nas pós-graduações dessas mesmas áreas também há pessoas de outros cursos.

Alguns autores aparecem em mais de uma produção. São eles: Vicente Faleiros (1981 e 2005), Marilda Iamamoto (2002 e 2007), Marina M. Abreu (2002 e 2009), Eblin Farage (2005 e 2009), Luiz A. Baldi (duas vezes em 2010) e Aline M. B. Machado (duas vezes em 2010). Cada um aparece duas vezes no quadro geral das produções, o que implica dizer que até 2010 são os que mais sinalizam ou aprofundam a articulação entre Serviço Social e educação popular. Ainda que só tenham uma produção a mais, ao aparecerem duas vezes na lista dos autores, isto significa que as sessenta produções equivalem a 54 autores diferentes, fora os coautores. 
Os resultados revelaram, ainda, treze cidades onde despontam as sessenta produções teóricas: São Paulo se destaca, apresentando 30\% das produções, seguido de Campina Grande, 20\%, Rio de Janeiro, 18\%, Brasília, 7\%, Porto Alegre e Florianópolis, 5\% cada, João Pessoa e Belém, 3\% cada, e, entre as demais cidades (Goiânia, Cuiabá, São Leopoldo, Juiz de Fora e São Luís), cada uma delas apresenta $2 \%$ das produções. As produções da década de 1980 se concentram sobretudo em Campina Grande, as dos anos de 1990, em São Paulo, e nos anos 2000, no Rio de Janeiro. Também foi possível observar que $50 \%$ das produções foram publicadas na região Sudeste, $25 \%$ no Nordeste, $12 \%$ no Sul, $10 \%$ no Centro-Oeste e 3\% no Norte.

Com relação aos temas transversais das produções pesquisadas, destacam-se: relações de gênero, crianças de rua, educação de jovens e adultos, escola pública, desenvolvimento de comunidade, trabalhos com grupos, ONGs, participação, produção do conhecimento, cultura e saúde. Os que não trazem temas transversais no título, apenas subtemáticas do próprio Serviço Social ou da educação popular (tais como: pensamento de Paulo Freire, popular, ações educativas, educação política, formação e/ou atuação profissional, projeto profissional, questão social e direitos sociais) equivalem à grande maioria das produções, revelando que a maior parte realizou especificamente o diálogo entre essas duas áreas (Serviço Social e educação popular) a partir de uma ótica teórico-metodológica crítica.

\section{Considerações finais}

Enfim, um panorama geral dos dados revela que: a grande maioria das produções investigadas advém de mulheres, é da década de 2000, expressa-se sobretudo em monografias de conclusão de graduação datadas nos anos 1980, provém da cidade de São Paulo, visto a hegemonia da Cortez Editora, decorre das regiões Sudeste e Nordeste, apresenta-se crítica e é, sobretudo, da área de Serviço Social, seguida da de Educação.

Ao tratar da importância do legado de Paulo Freire acerca da educação popular, Scheffer (2013, p. 293) assinala: "resgatar o legado de suas 
obras no Serviço Social significa entender a processualidade da ruptura com o pensamento conservador elitista na profissão e sua aproximação com o referencial marxiano e marxista". Na mesma linha de pensamento, Gomes (2011, p. 68) adverte: "O pensamento de Paulo Freire permanece instigante para aqueles que se desafiam a transformar a sociedade. Sua obra nos interpela, nos provoca, nos sacode". Portanto, compreendemos que é relevante não só resgatar a contribuição do pensamento de Freire acerca da educação popular, mas, sobretudo, captar quais elementos dessa prática educativa podem contribuir com a profissão de Serviço Social na contemporaneidade.

Iamamoto (2010, p. 200) afirma que os assistentes sociais precisam ter o conhecimento criterioso dos processos sociais e de sua vivência pelos indivíduos sociais, visto que isso poderá alimentar ações inovadoras. Aliás, tal "conhecimento é pré-requisito para impulsionar a consciência crítica e uma cultura pública democrática”. Com essa afirmação, a autora tanto estimula o desenvolvimento de pesquisas e projetos que favoreçam o conhecimento do modo de vida e de trabalho dos segmentos populacionais atendidos, como estimula os profissionais a impulsionarem a consciência política desses mesmos segmentos. Até porque a consciência política significa "a consciência de fazer parte de uma determinada força hegemônica é a primeira fase de uma autoconsciência, na qual a teoria e prática finalmente se unificam" (Gramsci, 1995, p. 21).

Mas, em termos técnico-operativos, podemos dizer que (no estímulo à consciência crítica e a uma cultura democrática) a metodologia da educação popular é fundamental, pois, ao mesmo tempo em que busca desvelar a realidade social e contribuir com o desenvolvimento da capacidade crítica das classes subalternizadas - a partir de categorias como diálogo, conscientização, práxis, participação, entre outras —, luta pelo protagonismo dos sujeitos sociais almejando a transformação social. Isso significa que esse tipo de educação, enquanto práxis educativa, visa estimular a práxis social, com vistas à transformação da sociedade. Daí defendermos o legado de Paulo Freire na história do Serviço Social brasileiro e atualidade de suas contribuições sobre educação popular. 


\section{Referências}

ABREU, Marina Maciel. Serviço social e organização da cultura: perfis pedagógicos da prática profissional. São Paulo: Cortez, 2002.

AGUIAR, Antônio Geraldo de. Serviço Social e filosofia: das origens a Araxá. 5. ed. São Paulo: Cortez, 1995.

ALMEIDA FILHO, Gilmar Alves de. Uma análise da relação entre Serviço Social e educação popular a partir da produção do conhecimento no curso de Serviço Social da UEPB na década de 1980. Monografia de Graduação - Universidade Estadual da Paraíba, Campina Grande, 2012.

ASSOCIAÇÃO BRASILEIRA DE ENSINO DE SERVIÇO SOCIAL (ABESS). Apresentação. Caderno Abess, 1988.

BATISTONI, Maria Rosângela. O Movimento de Reconceituação no Brasil: o Projeto Profissional da Escola de Serviço Social da Universidade Católica de Minas Gerais (19641980). Em Pauta, Rio de Janeiro, n. 40, 2017. Disponível em: <http://www.e-publicacoes. uerj.br/index.php/revistaempauta/issue/view/1640/showToc>. Acesso em: 26 jul. 2018.

FALEIROS, Vicente de Paula. Reconceituação do Serviço Social no Brasil: uma questão em movimento? Serviço social e sociedade n. 84. p. 21-36. São Paulo: Cortez, 2005.

FREIRE, Ana Maria Araújo. A voz da esposa - a trajetória de Paulo Freire. In: GADOTTI, Moacir (Org.). Paulo Freire: uma biobibliografia. São Paulo: Cortez/Instituto Paulo Freire; Brasília: Unesco, 1996.

FREIRE, Paulo. Política e educação. 8. ed. São Paulo: Villa das Letras, 2007.

Pedagogia da esperança: um reencontro com a pedagogia do oprimido. São Paulo: Paz e Terra, 2011.

GOMES, Maria de Fátima Cabral Marques. Paulo Freire e o Serviço Social no Brasil — elementos do pensamento freiriano para a superação do conservadorismo na profissão. Em Pauta, Rio de Janeiro, n. 27, 2011. Disponível em: <http://www.epublicacoes.uerj.br/ index.php/revistaempauta/article/view/2498>. Acesso em: 13 ago. 2017.

GOULART, Lucimere Valente Plaza. Estudo preliminar sobre a influência da fenomenologia no serviço social brasileiro. Em Pauta, Rio de Janeiro, n. 10, 1997.

GRAMSCI, Antonio. Concepção dialética da história. 10. ed. Rio de Janeiro: Civilização Brasileira, 1995.

IAMAMOTO, Marilda Villela. Projeto profissional, espaços ocupacionais e trabalho do assistente social na atualidade. In: CFESS. Atribuições privativas do(a) assistente social em questão. 2002. Disponível em: <http://www.cfess.org.br/arquivos/atribuicoes2012-completo.pdf>. Acesso em: 23 ago. 2013.

Serviço Social em tempo de capital fetiche: capital financeiro, trabalho e questão social. 4. ed. São Paulo: Cortez, 2010.

MACHADO, Aline Maria Batista. Serviço Social e educação popular: diálogos possíveis a partir de uma perspectiva crítica. Serviço Social \& Sociedade, São Paulo, n. 109, 2012. 
MACHADO, Aline Maria Batista. A relevância da educação popular para o serviço social. Educação Unisinos v. 17, n. 2. São Leopoldo, 2013. Disponível em: <http://revistas.unisinos.br/index.php/educacao/article/view/edu.2013.172.05/2014>. Acesso em: 2 dez. 2013.

NETTO, José Paulo. Ditadura e Serviço Social: uma análise do Serviço Social no Brasil pós-64. São Paulo: Cortez, 1991.

OLIVEIRA, Lucia Conde de, et al. Diálogos entre Serviço Social e educação popular: reflexão baseada em uma experiência científico-popular. Serviço Social \& Sociedade, São Paulo, n. 114, 2013.

OLIVEIRA, Valéria Costa Aldeci de. A influência do pensamento de Paulo Freire para o Serviço Social do Nordeste brasileiro - 1950 a 1963. Anais do IX Colóquio Internacional Paulo Freire. Recife, 2016. Disponível em: <http://coloquio.paulofreire.org.br/participacao/ index.php/coloquio/viii-coloquio/paper/view/382>. Acesso em: 25 ago. 2017.

SANTOS, Leila Lima. Textos de serviço social. São Paulo: Cortez, 1982.

Serviço Social na América Latina: 1970-1980. (Entrevista Memória). Em Pauta, Rio de Janeiro, n. 20, 2007. Disponível em: <http://www.e-publicacoes.uerj.br/index.php/ revistaempauta/article/view/167/193>. Acesso em: 24 jul. 2018.

SCHEFFER, Graziela. Pedaços do tempo: legado de Paulo Freire no Serviço Social. Textos e Contextos, Porto Alegre, v. 12, n. 1, 2013. Disponível em: <http://revistaseletronicas.pucrs. br/ojs/index.php/fass/article/viewFile/14152/10741>. Acesso em: 1 ago. 2017.

SILVA, Maria Ozanira da Silva e. (Org.). O serviço social e o popular: resgate teórico-metodológico do projeto profissional de ruptura. 6. ed. São Paulo: Cortez, 2009.

SPOSITO, Marília Pontes. O estado da arte sobre juventude na pós-graduação brasileira: Educação, Ciências Sociais e Serviço Social (1999-2006). Belo Horizonte: Argvmentvm, 2009. V. 1.

VARGAS, Tatiane Moreira. Serviço Social e educação popular: caminhos que se cruzam na direção de processos emancipatórios. Tese (Doutorado) - Pontifícia Universidade Católica do Rio Grande do Sul (PUC-RS), Porto Alegre, 2014.

\section{Sobre as autoras}

Aline Maria Batista MAchado - Doutora em Educação e Mestre em Serviço Social. E-mail: prof.alinemachado23@yahoo.com.br

AndrÊsa Melo da Silva - Bolsista de iniciação científica do Conselho Nacional de Pesquisa (Pibic-Cnpq).

E-mail: andresinha.melo@hotmail.com

Graziela Mônica Pereira Tolentino - Bolsista de iniciação científica do Conselho Nacional de Pesquisa (Pibic-Cnpq).

E-mail: grazielatolentino@gmail.com 